\title{
SUBACUTE BACTERIAL ENDOCARDITIS IN A YOUNG CHILD
}

\author{
BY \\ BERNARD LAURANCE \\ From the Belgrave Hospital for Children, London
}

(Received for Purucation May 22, 1950)

The incidence of subacute bacterial endocarditis in congenital heart disease is low. In the case reported below this condition was further complicated by bizarre embolic phenomena and is therefore considered worth recording.

\section{Relationship of Congenital Heart Disease to Subacute Bacterial Endocanditis}

Horder (1909) reviewed 150 cases of subacute bacterial endocarditis at all ages and found that congenital heart lesions were present in eight $(5 \cdot 3 \%)$. In 250 similar cases reviewed by Kelson and White (1945) there were $13(5.2 \%)$ congenital heart lesions, and in a further 88 cases seen between 1939 and 1944 White, Mathews and Evans (1945) recorded $12(13 \%)$, whilst Seabury (1947) put the incidence at 13 to $15 \%$ and Gartrell (1949) at $8 \%$. Kelson (1945) reviewed the literature between 1939 and 1944 and found mention of only eight cases of congenital heart lesions-excluding patent ductus arteriosus - in which subacute bacterial endocarditis was a complication.

Gelfman and Levine (1942) analysed 34,023 necropsies performed in various American hospitals and found that of the $453(1 \cdot 33 \%$ congenital heart lesions, subacute bacterial endocarditis occurred in $35(6 \cdot 6 \%$.

Incidence of Subacute Bacterial Endocarditis in Children

In cases where no congenital heart lesions are found, the incidence of subacute bacterial endocarditis is very low. Schlesinger (1928) in a review of necropsies performed between 1862 and 1927 at The Hospital for Sick Children, Great Ormond Street, found only 10 cases of this disease, and in a further 3,044 necropsies performed at the same hospital between 1928 and 1946 (Schlesinger and MacCarthy, 1949) there were only nine true examples of subacute bacterial endocarditis. From 1946 until December, 1949, there had been no further necropsies on this condition at The Hospital for Sick Children (Bodian, personal communication).
Age Incidence. The age incidence is variable, but the disease is rare in the very young. Of Horder's cases, only two were under 5 , the younger being $2 \frac{1}{2}$ years. A similar age incidence was found by Kelson and White, Libman and Friedberg (1941), Schlesinger, Seabury, and Gelfman and Levine. The last recorded subacute bacterial endocarditis complicating a patent interventricular septal defect in a 3-weeks-old girl.

\section{Involvement of Aortic Valves}

In children and adults the aortic valves are commonly affected. In Horder's series, which included the disease superimposed on rheumatic heart lesions, $22(14.6 \%)$ of his cases showed the aortic cusps only to be affected.

Abbott (1932) emphasized that bicuspid aortic valves in particular were very susceptible to this affection, and, as in the case reported below, rarely are the valves of equal size. White found bicuspid aortic valves in two of his cases with congenital heart lesions, and Gelfman and Levine noted that the case incidence of bicuspid aortic valves in the general necropsy population was $1.5 \%$, all in cases over 2 years of age, and that in $17.4 \%$ of these bacterial endocarditis was present.

Taussig (1947) considers that subacute bacterial endocarditis is the most frequent cause of death in aortic and subaortic stenosis.

\section{Incipient Onset}

In their review, Kelson and White stressed the mild way in which the disease may begin both in children and adults, common symptoms being listlessness, misery, and 'going off the legs'. In such cases, the predisposing cause is unknown, but respiratory infection, especially 'grippe' and the common cold, and of course dental extractions, are important aetiological factors. They also mention that 'in persons with pre-existing valvular or congenital heart disease, streptococci viridans usually disappear from the blood quickly and without harmful effect, but they may implant in crevices of 
the endocardium, become surrounded with platelets and fibrin, and establish bacterial endocarditis.'

\section{Case Report}

A boy, aged 2 years and 10 months, was originally referred to hospital in September, 1948, on account of a cardiac murmur found at a routine examination.

His mother's pregnancy had been normal, and his birth weight was $7 \mathrm{lb} .11 \mathrm{oz}$. Apart from having been slightly underweight, he had been perfectly well and was then $31 \mathrm{lb}$., a normal weight for his age. Clinical examination at this time revealed a normal-sized heart, a thrill at the base, and a harsh systolic murmur maximal over the centre of the praecordium conducted up to the neck. A provisional diagnosis of aortic stenosis was made.

Radiological examination of the chest showed the general contour of the heart to be within normal limits.

On February 3, 1949, he returned to hospital because two months previously (i.e. at the age of 3 years 1 month) he had become listless, miserable, and pale, had lost his appetite, perspired unduly, and 'went off his legs '.

On admission to the Belgrave Hospital for Children he was very pale, sweating and lethargic. His temperature rose daily from $98 \cdot 4^{\circ} \mathrm{F}$. in the morning to $103 \cdot 4^{\circ} \mathrm{F}$. at night. Early finger clubbing was present. The heart was now slightly enlarged judged by the apex beat, but otherwise cardiac signs were as noted in September, 1948. The spleen was palpable, but there was no evidence of emboli.

Results of investigations at this time were: haemoglobin $46 \%$ (7-18 g., Haden); W.B.C.s 14,600 per c.mm. (neutrophils $73 \%$, lymphocytes $18 \%$, monocytes $9 \%$ ); B.S.R. $55 \mathrm{~mm}$. in 1 hour (Wintrobe). A radiograph of the chest showed generalized cardiac enlargement without changes in the lung fields. The tuberculin jelly test was negative. Streptococcus viridans was grown from a blood culture taken on February 9. Urine was normal with no microscopic haematuria.

Treatment. On February 10 intramuscular injections of penicillin, 200,000 units four-hourly, were begun, and after two weeks the child's temperature settled, but rose again after a further 12 days, and so on February 22 the dosage was raised to 500,000 units four-hourly. Fourteen days after the increased dose, his temperature became normal and remained so for seven weeks. On March 11 a blood transfusion of $180 \mathrm{ml}$. of packed cells was given which raised his haemoglobin to $70 \%$, at which it remained. On March $\mathbf{3 0}$ the penicillin dosage was reduced to 500,000 units q.d.s. The total dosage of penicillin was 158 million units.

Few embolic episodes were noticed. Occasionally he complained of pain in the region of his spleen, which was tender, though no rub was ever heard. His urine was examined microscopically on frequent occasions, but only once were numerous red cells found. Blood culture was repeater on February 24 and on four subsequent occasions, and was consistently sterile.

Throughout this time the murmurs as originally noted had not altered, though two months after his admission he was found to have a collapsing pulse, a slight clinical cardiac enlargement and an aortic diastolic murmur, which, a month later, had disappeared. On April 1, a week after this murmur was first noted, he developed pain and loss of movement of his right wrist joint and elbow, but 14 days later these symptoms had disappeared. On April 11 his penicillin was stopped, but 12 days later his temperature rose, and beginning April 26 the penicillin, 500,000 units q.d.s., was given for a further six days, once again rendering him afebrile.

A week later the child again became unwell and again an aortic diastolic murmur was noted. That same night he had a sudden onset of pain in the right thigh, and although pulsation could easily be felt in the right femoral artery, it was absent in the corresponding popliteal and dorsalis pedis vessels. His right leg was discoloured and colder than the left, though it returned to normal within 48 hours.

Seventeen days later, on May 25, a further embolic episode was noted by one of the nurses, who reported that she was unable to feel his right radial pulse. This was confirmed, and in addition pulsation was found to be absent in the brachial artery. Despite these phenomena, his general condition improved after a further blood transfusion on June 1 of $200 \mathrm{ml}$. of packed cells.

The child became very lively, ran about the ward without a limp, and showed no disability in his right arm. He was given another transfusion of $300 \mathrm{ml}$. of packed cells on July 1 , raising his haemoglobin to $84 \%$ ( $13 \cdot 1 \mathrm{~g}$.). His heart now showed definite clinical enlargement to the left, and on auscultation an aortic systolic and diastolic murmur was heard, the systolic murmur conducted to the mitral area. With these findings he was discharged home after $5 \frac{1}{2}$ months in hospital.

Three weeks later be was readmitted because he had been unwell and vomited for $\mathbf{4 8}$ hours.

Examination then revealed a very dyspnoeic, restless, pale child with a temperature of $98^{\circ}$, and pulse 135 a minute. His heart was clinically grossly enlarged, confirmed by radiographs which showed a certain amount of vascular congestion in the lungs, although at this time there were no signs of right-sided heart failure. Blood tests gave: haemoglobin $58 \%\left(9.05\right.$ g. ${ }^{\circ}$ o); R.B.C.s $2,800,000$ per c.mm.: colour index 1.03 ; W.B.C.s 9,240 per c.mm. (neutrophils $56 \%$, lymphocytes $42^{\circ}$, large mononuclears $2 \%$ ).

The child remained very ill, and the next day developed an irregular pulse, distended neck veins, and an enlarged liver. He died the same day, nine months after the onset of illness.

Necropsy. Necropsy was performed by Dr. B. S. Cardell, King's College Hospital Medical School, and his report follows.

The body was that of a thin male child showing slight cyanosis of the face and extremities. There was no oedema or abnormal pigmentation.

The heart was much enlarged, weighing 235 g. (normal 60 g.) with marked left ventricular hypertrophy, the myocardium attaining a maximum thickness of $1.2 \mathrm{~cm}$. The aortic valve was bicuspid, the two cusps being of unequal size. A moderate degree of aortic stenosis was produced by the rigid and distorted cusps, from which 
large calcareous vegetations projected. The left ventricular endocardium was roughened immediately below the left aortic cusp. The aortic valve ring itself was not stenosed, measuring $6.1 \mathrm{~cm}$. in circumference. The ascending aorta was slightly dilated $(5.9 \mathrm{~cm}$. in circumference), and on the posterior wall $3 \mathrm{~cm}$. above the valve ring there was a roughly circular atheromatous plaque $2 \mathrm{~cm}$. in diameter (Figs. 1 and 2).

The lungs (left $195 \mathrm{~g}$., right $275 \mathrm{~g}$.) were congested and poorly aerated, with no evidence of infarction. The liver was congested (550 g.). The spleen was slightly enlarged ( $75 \mathrm{~g}$.) and showed one small old infarct. There were two small, old infarcts in the left kidney and one in the right. The right femoral artery was obliterated $5 \mathrm{~cm}$. above the knee, being represented for a distance of $0.5 \mathrm{~cm}$. by a fibrous cord and in the lower axilla the right brachial artery was similarly obliterated.

Sections of the kidneys and myocardium revealed no evidence of active lesions.

\section{Discussion}

Several interesting features of subacute bacterial endocarditis are illustrated by this case and by the literature.

Rarity in Chidhood. Subacute bacterial endocarditis is rare in childhood and especially in such a young child as this case.

Incidence in Heart Lesions. Subacute bacterial endocarditis occurs in approximately $5-15 \%$ of congenital heart lesions and is the most frequent cause of death in aortic and subaortic stenosis. Bicuspid aortic valves are especially susceptible to this disease.

Embolic Phenomena. Wagner (1948) mentions that cerebral embolism is an occasional unpredict-

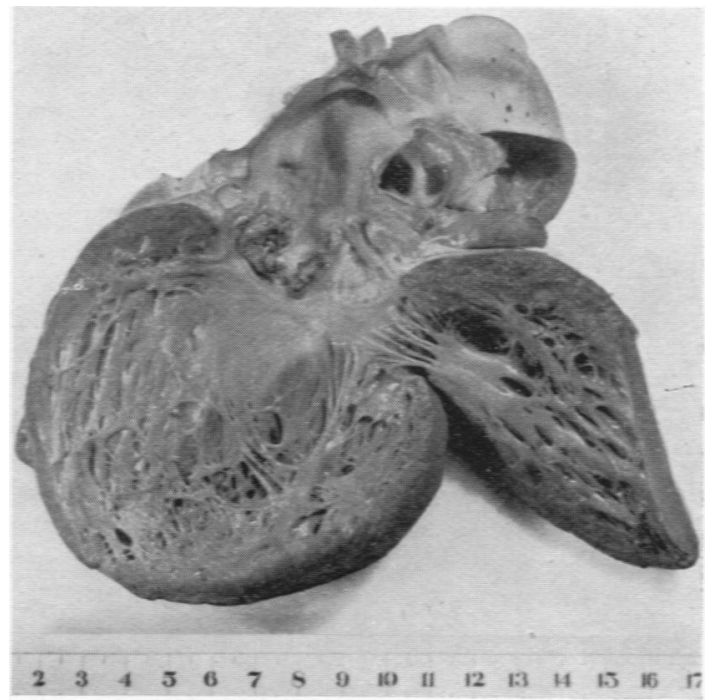

Fig. 1.-Enlarged heart with marked left ventricular hypertrophy.

able cause of death during prolonged therapy, and that emboli are responsible for infarcts in other organs.

Williams and Nelson (1949) found emboli which were clinically renal, pulmonary or cerebral, but no necropsies were done on these cases. In three of their 12 cases treated with penicillin, petechiae and/or embolic phemonena were noted several days or weeks after blood cultures became sterile.

FIG. 2.-Large vegetations projecting from bicuspid aortic valve. Circular atheromatous plaque in ascending aorta.

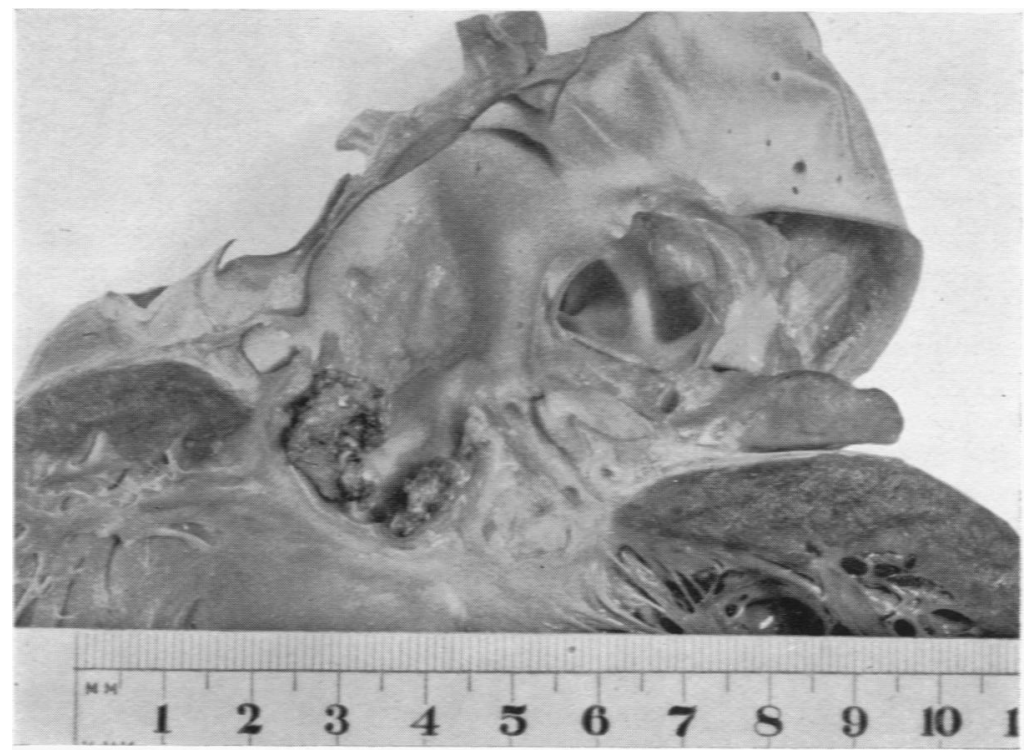


In the 165 patients reviewed by Seabury, embolism occurred in $57 \%$ of all cases, both in rheumatic and congenital heart lesions.

The arrest of the disease after vast doses of penicillin is liable to lull one into a false sense of security, and any vegetations formed, although sterile, are still very friable and therefore liable to break off from their attachment. In this child's arm and leg there was an efficient collateral circulation following complete occlusion of the main arteries by emboli.

Residual Cardiac Damage. The increase in residual cardiac damage after apparent cure of the infection has been emphasized by Morgan Jones, Herring, Langley, and Oleesky (1947). These authors also noted that the duration of the disease before the beginning of treatment was the most important factor in prognosis.

From evidence found at necropsy in this case, it would seem that the stenosis increased as the vegetations fibrosed, eventually causing heart failure.

Thrill and Meyer (1947) mention that in healed endocarditis the vegetations undergo fibrous organization.

Results of Penicillin Therapy. Christie (1948) summarized the results of treatment of this condition with penicillin in 269 patients at 14 centres in Great Britain. He noted that of the 94 patients in whom the infection was apparently controlled, but who subsequently died, 45 died of heart failure, and this was a major cause of death in a further 14 . Nine died as a result of emboli.

The heart valves were examined in 47 cases, in 39 of which infection appeared controlled. In this group, however, presumed living organisms were seen in the heart valves of 13; organisms of uncertain viability in four; and apparently dead organisms in nine. In the remaining eight patients, infection was not clinically controlled, though in two no organisms could be demonstrated.

These patients were further followed up (Christie, 1949) for another two years, and, in addition 139 new cases were reported. The factors mentioned in the first report as affecting the cause of death were confirmed, but the original suggested dosage of 500,000 units of penicillin daily for one month was revised to a dose of $2,000,000$ units a day for four to six weeks.

Seabury's review covers a period before and after the advent of penicillin. Of 12 patients treated with penicillin, seven $(58 \%)$ had probably been cured (i.e., these were well after a minimum period of one year). He thought that the reports available at the time indicated that penicillin could be expected to be efficacious in from 65 to $70 \%$ of cases of subacute bacterial endocarditis.

Wagner analysed 521 cases in the literature treated with penicillin. Clinical arrest occurred in 371 $(71 \cdot 3 \%)$ and in an additional $95(18 \cdot 2 \%)$ a cure was produced in the hospital, but the disease recurred and the patients died within three to four months. The remaining $55(10.5 \%)$ were complete clinical failures.

\section{Summary}

A case of congenital aortic stenosis in which subacute bacterial endocarditis occurred at the early age of 3 years is recorded. Although apparently cured of the infection, the child suffered embolic occlusion of the brachial and femoral arteries. Seventeen days after discharge from hospital he died of heart failure due to an increasing aortic stenosis, the result of fibrosis of vegetations on the aortic valve. The literature is discussed.

I wish to thank Dr. Mary Wilmers, under whose care this child was admitted, for very helpful criticism and for permission to publish, and Prof. H. A. Magnus for permission to describe the necropsy. Dr. N. F. Elliott Burrows kindly corrected the draft manuscript for me.

\section{REFERENCES}

Abbott, M. E. (1932). 'Contributions to the Medicalo' Sciences in Honour of Dr. Emanuel Libman,? vol. 1, p. 1. New York.

Christie, R. V. (1948). Brit. med. J., 1, 1.

- (1949). Ibid., 2, 950.

Gartrell, E. F. (1949). Med. J. Aust., 1, 353.

Gelfman, R., and Levine, S. A. (1942). Amer. J. med. Sci., 204, 324.

Horder, T. J. (1909). Quart. J. Med., 2, 289.

Jones, A. Morgan, Herring, R., Langley, F. A., and Oleesky, S. (1947). Brit. Heart J., 9, 38.

Kelson, S. R. (1945). Ann. intern. Med., 22, 75.

, and White, P. D. (1945). Ibid., 22, 40.

Libman, E., and Friedberg, C. K. (1941). 'Subacute Bacterial Endocarditis.' New York.

Seabury, J. H. (1947). Arch. intern. Med., 79, 1.

Schlesinger, B. E. (1928). Brit. J. Child. Dis., 25, 33. and MacCarthy, D. (1949). In Garrod, Batten, and Thursfield's 'Diseases of Children,' vol. 2. London.

Taussig, H. B. (1947). 'Congenital Malformations of the Heart.' New York.

Thrill, C., and Meyer, O. (1947). Amer. J. Med. Sci., $213,300$.

Wagner, B. M. (1948). I Ibid., 215, 84.

White, P. D., Mathews, M. W., and Evans, E. (1945). Ann. intern. Med., 22, 61.

Williams, R. K., and Nelson, K. (1949). Va. med. Mon., 76, 589. 